\title{
Collaborative competence, social capital, and mental health: A cross-sectional analysis of a community-based intervention for older adults
}

\section{Annahita Ehsan $^{1,2}$ (1) | Nicolas Sommet ${ }^{1,2}$ () | Davide Morselli ${ }^{1,2}$ (1) | Dario Spini ${ }^{1,2}$}

${ }^{1}$ University of Lausanne, Lausanne, Switzerland

${ }^{2}$ Swiss Centre of Expertise in Life Course Research LIVES, Lausanne, Switzerland

\section{Correspondence}

Annahita Ehsan, Batiment Géopolis, Institute of Social Sciences, University of Lausanne, Lausanne, Switzerland.

Email: annahita.ehsan@unil.ch

\begin{abstract}
Social capital interventions for the mental health of older adults have been inconclusive to date, and have rarely investigated the psychological resources that are important to having social capital. This study focused on the "Neighborhoods in Solidarity" (NS), which are a series of Swiss community-based interventions that aim to empower older adults to participate in their communities. Our goal was to understand whether the NS were associated with collaborative competence, social capital, and subsequently, symptoms of depression. Cross-sectional data were collected from 947 individuals aged 55 and over $\left(M_{\text {age }}=68.66\right.$, $S D=9.04$ ) in 10 Swiss neighbourhoods (five with the NS [ $n=479]$ and five control neighbourhoods [ $n=468]$ ). Structural equation modelling was used to model the relationship between the NS intervention, collaborative competence, cognitive and structural dimensions of social capital, and symptoms of depression (measured by the CESD-R-10). Individual participation in the NS had total and indirect effects on symptoms of depression via collaborative competence and both social capitals. These findings suggest that existing community-based interventions can be indirectly associated with better mental health outcomes in the ageing population.
\end{abstract}




\section{KEYWORDS}

collaborative competence, community intervention, mental health, older adults, social capital

Community-based participatory interventions (CBPI) may promote social capital (SC) and mental health among older adults. SC refers to the quality and quantity of social relationships that individuals or groups possess (Kawachi \& Berkman, 2000). SC interventions, which strengthen social relationships between individuals and groups in a given community (Ehsan, Klaas, Bastianen, \& Spini, 2019), can have positive consequences for the mental health of older adults, and can protect against the onset of mental illness (Bojorquez-Chapela, Manrique-Espinoza, Mejía-Arango, Solís, \& Salinas-Rodríguez, 2012; Murayama et al., 2013). Research concerning SC interventions for mental health in the ageing population seems promising, but evidence of their effectiveness has been inconclusive to date (CollPlanas et al., 2017), and it is unclear as to whether SC interventions really build SC (Ehsan et al., 2019).

One problem may be that SC interventions in published research rarely use CBPI (Shiell, Hawe, \& Kavanagh, 2018). CBPI often focus on co-learning and creating change through active involvement and participation from all members. Community research has stressed the importance of participatory designs, as they foster individual and group capabilities that enable actors to be active agents of change in their own communities (Botes $\&$ Van Rensburg, 2000; Duraiappah, Roddy, \& Parry, 2005). Despite consideration in health promotion initiatives (Wallerstein \& Duran, 2006), these approaches have been largely ignored in the SC and health literature (Shiell et al., 2018). We argue that Christens' (2012) understanding of collaborative competence (the ability to create relationships that lead to group membership and solidarity) can be useful to studying if some existing CBPI can indirectly promote SC, and subsequently mental health. Indeed, a recent call to action recommended studying social interventions that are not intended for mental health, but can have implications for mental health promotion (Burgess, Jain, Petersen, \& Lund, 2020). We collaborated with an existing organization to conduct a natural experiment in order to study a series of CBPI and their relationship with collaborative competence, SC, and mental health in communities of older adults in Switzerland. Our first goal was to test the direct (formally, total) effect of these interventions on the mental health of older adults. Our second goal was to test the indirect effects of these interventions on mental health via collaborative competence and two dimensions of SC.

\section{1 | SC AND MENTAL HEALTH}

Social relationships are known predictors of health and of mortality (Steptoe, Shankar, Demakakos, \& Wardle, 2013), and SC can protect against the onset of depression in older adults (Bojorquez-Chapela et al., 2012; Murayama et al., 2013). Here, SC distinguishes between two dimensions: Cognitive and structural. Cognitive (perceived) SC refers to the values, norms, attitudes, beliefs, altruism, and reciprocity within a community, whereas structural (participatory) SC refers to networks, relationships, and memberships in organizations or institutions that can link groups and individuals together. Each of these dimensions exists at the individual and at the group level. For individuals, cognitive SC can be measured using indicators such as social trust or social cohesion, and structural SC can be measured by membership in various groups. Group measures of both SCs are often individual measures that are aggregated to a set geographic area, such as a neighbourhood (McKenzie \& Harpham, 2006). A systematic review of SC and mental health found that cognitive SC protected against common mental disorders, whereas the effects of structural SC are mixed and depend more on specific contexts (Ehsan \& De Silva, 2015). Recent evidence has shown that the mixed effects of group memberships on mental health are due to a curvilinear relationship, and that moderate (as opposed to too little or too much) individual participation is associated with better mental health outcomes (Gallagher et al., 2019). 
An SC intervention is defined as any intervention that aims to strengthen social relationships in a given community by increasing connections and/or cooperation within and/or between community members. These social relationships can elicit feelings of trust, reciprocity, or shared identity, and can increase access to shared resources (Flores et al., 2018). While SC interventions seem promising for health promotion, a systematic review assessing the health impact of SC interventions in the ageing population showed that findings were mostly inconsistent with respect to depression and anxiety (Coll-Planas et al., 2017). Moreover, a meta-analysis found that participating in social activities had a small but significant negative effect on depressive symptoms in seniors, but that the effect became null when considering categorical diagnosis of depression (Forsman, Nordmyr, \& Wahlbeck, 2011). Overall, there is inconsistent evidence on whether SC interventions increase SC, and the mechanisms that link these interventions to mental health (Ehsan et al., 2019). The lack of frameworks that clearly show how SC interventions are linked to mental health must be further explored.

At least five key factors could explain why research on SC interventions for mental health has been inconsistent. Most research has focused on short-term interventions, lasting 12 months or less (Coll-Planas et al., 2017; Flores et al., 2018). This may not provide enough time to build lasting SC and to see changes in symptoms of depression. Furthermore, synthesizing evidence on SC interventions is problematic, as they vary in contexts and need to be tailored to specific populations. For example, the review by Flores et al. (2018) compared broader populations such as deprived urban communities in the UK (Phillips et al., 2014) to more targeted populations like survivors of sexual violence in the DRC (Hall et al., 2014). In the ageing population, the review by Coll-Planas et al. (2017) synthesized SC interventions that were designed for individuals with different levels of cognitive functioning in various contexts, including the general community, nursing homes, and even hospitals. Moreover, researchers have relied on different conceptualizations of SC: What has fallen under the umbrella term of SC interventions have ranged from socialidentity mapping (Haslam, Cruwys, Haslam, Dingle, \& Chang, 2016), to locally adapted cognitive processing therapy (Hall et al., 2014), to educational, cognitive, and social support programs (Saito, Kai, \& Takizawa, 2012). Researchers have also designed SC interventions using their own theoretical lenses (often implying a top-down approach), which may limit the identification of a community's specific needs. These needs would be better identified using a participatory, bottom-up approach: Research should focus on SC interventions that use CBPI for health promotion (Shiell et al., 2018). Finally, psychological processes are rarely taken into account when evaluating SC interventions for mental health. For example, SC and health research has not considered the self and collective efficacies that individuals and groups develop as they participate in CBPI (Christens, 2012). Further research is needed to understand the psychological resources that contribute to developing SC, in order to inform SC interventions for mental health.

\section{I COLLABORATIVE COMPETENCE AS A MECHANISM FOR BUILDING SC}

One possible mechanism that can explain how SC interventions predict mental health is through psychological resources. Psychological resources are antecedents of SC (Perkins, Hughey, \& Speer, 2002), but research on SC interventions for mental health has not adequately considered the psychological mechanisms by which SC is created. Specifically, the psychological processes that contribute to an individual's ability to build SC remain unclear (Ehsan et al., 2019). While not all CBPI foster SC, we argue that some may create conditions that psychologically support the ability of an individual (or group) to build SC.

We turn to Christens' (2012) theory of relational empowerment, and more specifically collaborative competence, to help explain how CBPI helps build psychological resources (in this case, collaborative competence) that may help individuals improve or create SC. Collaborative competence is a component of relational empowerment (the psychological aspects of interpersonal interactions that help exercise power), and is defined as "the set of abilities and propensities necessary for the formation of interpersonal relationships that can forge group membership and solidarity" (Christens, 2012, p. 121). Simply put, it can be understood as the ability to create well-functioning relationships of 
solidarity (Ellison, 2017), which we argue could be a precursor that leads to SC. It is important to theoretically distinguish the two concepts: Collaborative competence focuses on the set of abilities that individuals have to form relationships, whereas SC focuses on the presence of these relationships within a given community. Similar to SC, collaborative competence can be found within individuals and groups: Both Zimmerman (2000) and Christens (2012) stress that the psychological empowerment of individuals and communities are inextricably connected, and that both stem from an interaction between individuals and the socio-cultural contexts in which they live. Therefore, promoting aspects of collaborative competence could benefit both individuals and the groups that they are members of. We argue that promoting both individual- and group-level collaborative competence could potentially influence both individual and group levels of SC.

Collaborative competence is rooted in community processes, and can be nurtured through various communitybased and participatory approaches (Christens, 2012). Few empirical studies have looked solely at collaborative competence, and research on relational empowerment has been mostly exploratory to date (Christens, Winn, \& Duke, 2016). Existing empirical studies on relational empowerment have shown that children participating in a participatory after school program experienced an increased collaborative competence (Langhout, Collins, \& Ellison, 2014), but this may not hold true in other contexts or for other populations, such as older adults. Empirical research has yet to investigate the link between collaborative competence and SC, and understanding this relationship could have important implications for future SC interventions.

Collaborative competence may be one psychological mechanism that could help understand if some CBPI can also promote SC in communities. If an individual has the abilities necessary to form social relationships, they may be more likely to participate in community groups and associations (structural SC). Similarly, individuals with high collaborative competence may perceive higher cohesion in their neighbourhood (cognitive SC). Building collaborative competence could, therefore, lead to cognitive and structural SC, and by extension, positive mental health outcomes.

One way to understand these relationships is to conduct natural experiments that focus on existing CBPI that foster collaborative competence, and subsequently SC. Adding a measurement component to such interventions can provide a series of natural experiments to investigate the relationships between aspects of collaborative competence, SC, and mental health for both individuals who participate in the intervention, as well as the groups that they are members of.

\section{3 | NEIGHBOURHOODS IN SOLIDARITY}

Research on SC interventions for the mental health of older adults has focused on short-term, top-down approaches, and has rarely considered psychological processes that are important to having SC. This study focuses on the relationships between a series of long-term CBPI for older adults. It considers collaborative competence as a possible mechanism to explain how the intervention may indirectly promote $\mathrm{SC}$, and subsequently mental health.

This study focuses on the "Neighborhoods in Solidarity" (NS). The NS are a series of CBPI that useactionresearch methodology with older adults aged 55 and over, in their own communities in the French-speaking canton of Vaud, Switzerland. The proportion of older adults in Vaud is rapidly increasing, with an estimated $120 \%$ increase of adults over the age of 80 by 2040 (Büla et al., 2012). The canton of Vaud recommended developing social participation interventions for healthy ageing, and are committed to understanding how social and ecological determinants play a role in local health promotion and prevention (Canton de Vaud, 2018).

The objectives of the NS are to (a) empower older adults to participate in their neighbourhoods, (b) develop solidarity within neighbourhoods, and (c) improve overall quality of life for residents in that neighbourhood (Zwygart, Plattet, \& Spini, 2018). The NS approach encourages community members (including the general population, association representatives, and various professionals) to come together. Municipalities request and fund the intervention for specific areas, and residents within those areas create and lead the intervention with the help of a socio-cultural facilitator. In the first stages, residents meet every 2-3 weeks to identify what they want to change in their 
geographically defined community (locally targeted intervention). Residents discuss their needs as a group, and NS professionals help residents take initiative, suggest solutions, and organize activities that address these needs. Residents eventually choose and lead activities for other members in their neighbourhoods. The number and type of activities offered vary based on the needs identified by each NS, but regular activities across NS interventions include walking groups, games groups, coffee meet-ups, group meals, language exchanges, information technology clubs, and large group outings. The NS professionals aim to keep all residents aged 55+ in the NS target areas informed of the activities by sending them information directly to their homes. The NS have been on-going in over 20 different neighbourhoods and villages in Vaud since 2002, and last approximately 3-5 years each (Zwygart et al., 2018).

The NS help enables individuals to work together to put activities that will benefit their communities in place. We expect that organizing such activities will be related to collaborative competence. By providing individuals with the ability to create supportive social relationships, the NS also provide a framework that allows individuals living in a neighbourhood to cultivate SC for themselves and their neighbours. The NS could subsequently promote mental health for individuals who participate and other neighbourhood residents.

\section{4 | RESEARCH QUESTIONS AND HYPOTHESES}

This study aimed to understand whether the NS are associated with collaborative competence, cognitive and structural SC, and symptoms of depression in a natural setting for individuals aged 55 and over. We hypothesized two models that describe how the NS could predict symptoms of depression. We used two separate focal predictors (i.e., main variable of interest): Model 1 looked at individual participation in the NS, and Model 2 looked at whether there is a NS in the neighbourhood. In model 1, we expected that individuals who participated in the NS activities would have higher levels of collaborative competence and both types of SC. In model 2, we expected that having an NS in a neighbourhood could contribute to the number of activities that were available in a given community, which could predict individuals' awareness of what is going on, even if they themselves did not participate. This would be due to NS outreach, which invites all residents in NS neighbourhoods to participate in various activities. We would not expect the municipality as a whole to benefit from the effects of the NS intervention, as the NS are targeted locally, and only reach out to individuals who live within the neighbourhood. Our two models hypothesized that (a) participating in the NS and (b) living in an area with an NS would be associated with cognitive and structural SC, directly and indirectly via collaborative competence. We hypothesized that collaborative competence and having more of both cognitive and structural SC would be associated with less symptoms of depression. To summarize, we expect that the NS will predict collaborative competence, which will predict SC, which can, in turn, predict the symptoms of depression.

\section{5 | METHODS}

\section{1 | Participants and procedure}

\subsection{1 | Sampling procedure}

This study was conducted in 10 different neighbourhoods in three urban municipalities in the canton of Vaud, Switzerland: Yverdon-les-Bains, Gland, and Morges. We randomly sampled 1,800 individuals' aged 55 and over using civil registries from each of the following municipalities: 600 individuals from Yverdon-les-Bains (population 55+: 8,483), 600 from Morges (population 55+: 4,923), and 600 from Gland (population 55+: 2,799) (Statistique Vaud, 2017). Civil registries in Switzerland comprise of every individual with an address, and are updated every time a person moves. Half of the individuals we sampled lived in five neighbourhoods with a NS in their neighbourhood (Pierre-de-savoie, 
Moulins, Villette) or town (Gland-Nord, Gland-Sud). A list of estimated total participants, as well as the number of activities offered in each NS, is provided in Table 1. The other half lived in five control neighbourhoods without an NS in their neighbourhood (Bains, Général-Guisan, Quatre-Marroniers) or town (Morges-Nord, Morges-Sud; i.e., 300 individuals per neighbourhood).

Control neighbourhoods were selected based on similarities with the intervention neighbourhoods in terms of town and neighbourhood type (residential, central, etc.), population size, services available in the area, and other socio-economic development indicators. Each individual received a letter explaining the study, a questionnaire, and a pre-stamped return envelope designating which neighbourhood the questionnaire had come from. The letter explained that the study was voluntary, treated anonymously, and that returning the filled questionnaire would imply the participant's informed consent. The Swiss Ethics Committees on research involving humans in the canton of Vaud approved this study.

\subsection{2 | Participants}

A total of 1,070 individuals returned the completed questionnaire (59.44\% response rate). We excluded 123 participants due to missing data on our variables of interest (32 on participation in the NS, 38 on symptoms of depression, 39 on SC, and eight on collaborative competence), as well as six participants for being too young (less than 55 years old). The final sample consisted of 947 individuals in 10 neighbourhoods of three separate municipalities (447 men, 497 women, and 3 unspecified; $M_{\text {age }}=68.66, S D=9.05$ ). A sensitivity analysis conducted with $G^{*}$ Power 3.1 (Faul, Erdfelder, Buchner, \& Lang, 2009) revealed that a sample size of $N=947$ was sufficient to detect a very small-sized effect (i.e., $f^{2}=.008$ ) with a power of .80 and a nominal alpha of.05.

The respondents' socio-demographic characteristics are in Table 2, and characteristics related to the NS are in Table 3. In one municipality, neighbourhoods with the NS were close to control neighbourhoods. This meant that some individuals from neighbourhoods with no NS participated in the NS (Table 3). However, there was an overall significant relationship between participating in the NS and living in an NS neighbourhood, $\chi^{2}(1, N=533)=12.0, p<.001$.

\section{$5.2 \mid$ Measures}

In the following section, we describe each of our measures with reference to the individuals who responded. For mean measures per neighbourhood concerned, please see Appendix A in Data S1.

TAB LE 1 Estimated NS activities and outreach per neighbourhood, from NS statistics

\begin{tabular}{|c|c|c|c|c|c|c|}
\hline \multirow[b]{2}{*}{ NS project } & \multirow[b]{2}{*}{ NS stage } & \multirow[b]{2}{*}{$\begin{array}{l}\text { Number of } \\
\text { activities }\end{array}$} & \multicolumn{4}{|c|}{ Participants } \\
\hline & & & $\begin{array}{l}\text { Highly } \\
\text { active }\end{array}$ & $\begin{array}{l}\text { Participated in at } \\
\text { least one activity }\end{array}$ & $\begin{array}{l}\text { Are } \\
\text { informed }\end{array}$ & $\begin{array}{l}\text { Total } \\
\text { possible } \\
\text { outreach }\end{array}$ \\
\hline $\begin{array}{l}\text { Yverdon-les-Bains: } \\
\text { Pierre-de-Savoie }\end{array}$ & $\begin{array}{r}\text { Autonomous } \\
\text { since } 2011\end{array}$ & 6 & 10 & 200 & 1,800 & 1,800 \\
\hline $\begin{array}{l}\text { Yverdon-les-Bains: } \\
\text { Villette }\end{array}$ & $\begin{array}{r}\text { Autonomous } \\
\text { since } 2014\end{array}$ & 5 & 10 & 100 & 310 & 1,500 \\
\hline $\begin{array}{l}\text { Yverdon-les-Bains: } \\
\text { Moulins }\end{array}$ & $\begin{array}{l}\text { On-going as } \\
\text { of } 2014\end{array}$ & 5 & 20 & 100 & 2,473 & 2,473 \\
\hline $\begin{array}{l}\text { Gland: North and } \\
\text { south }\end{array}$ & $\begin{array}{r}\text { Autonomous } \\
\text { since } 2014\end{array}$ & 20 & 30 & 300 & 2,200 & 13,000 \\
\hline Total participants & & & 70 & 700 & 6,783 & 18,773 \\
\hline
\end{tabular}


TABLE 2 Sample socio-demographic characteristics

\begin{tabular}{|c|c|c|}
\hline Demographic characteristics & $\mathrm{n}$ & $\%$ \\
\hline \multicolumn{3}{|l|}{ Education } \\
\hline Primary school & 101 & 10.72 \\
\hline Lower secondary school & 36 & 3.82 \\
\hline Apprenticeship & 353 & 37.47 \\
\hline Upper secondary school & 149 & 15.82 \\
\hline Higher professional training & 128 & 13.59 \\
\hline University & 136 & 14.44 \\
\hline Other & 39 & 4.14 \\
\hline Total & 942 & 100.00 \\
\hline \multicolumn{3}{|l|}{ Employment status } \\
\hline Employed & 187 & 19.79 \\
\hline Independent work & 39 & 4.13 \\
\hline Stay at home partner & 53 & 6.61 \\
\hline Retired & 610 & 64.55 \\
\hline Unemployed or disability & 30 & 3.17 \\
\hline Other & 26 & 2.75 \\
\hline Total & 945 & 100.00 \\
\hline \multicolumn{3}{|l|}{ Nationality } \\
\hline Swiss & 828 & 89.80 \\
\hline European & 83 & 9.00 \\
\hline Outside Europe & 11 & 1.19 \\
\hline Total & 922 & 100.00 \\
\hline
\end{tabular}

Note: There are four missing values for education, two for employment status, and 25 for nationality.

\subsection{1 | Neighbourhood in solidarity}

Through adopting a natural experiment approach, the neighbourhood variable was measured by whether or not individuals lived in a neighbourhood with the NS intervention. ( $0=$ no NS [ $n=479,50.58 \%], 1=N S[n=468,49.42 \%]$ ). On average, the NS had been in each neighbourhood for 3.17 years $(S D=3.56)$.

\subsection{2 | Participation in the NS}

An individual's participation in the NS was determined by whether or not they participated in the NS $(0=$ did not participate [ $n=876,92.50 \%], 1$ = participated [ $n=71,7.50 \%]$ ). On average, individuals had participated in the NS for 3.98 years $(S D=2.65)$, their frequency of participation in NS activities (ranging from $0=$ never to $4=$ more than five times a week) was $M=0.56(S D=1.11)$.

\subsection{3 | Collaborative competence}

Collaborative competence was measured using an adapted version of Jeanrie's (1997) five-item scale for feelings of self-efficacy (e.g., "would you be able to get together with your neighbors in order to improve your neighborhood", 
TABLE 3 Individual participation in the NS and neighbourhood characteristics

\begin{tabular}{|c|c|c|c|c|c|c|}
\hline & & \multicolumn{3}{|c|}{ Individual participation } & \multicolumn{2}{|c|}{$\begin{array}{l}\text { Neighbourhood } \\
\text { participation }\end{array}$} \\
\hline & & $\begin{array}{l}\text { Did not } \\
\text { participate }\end{array}$ & Participated & Total & $\begin{array}{l}\text { Time NS } \\
\text { (years) }\end{array}$ & $\begin{array}{l}\text { NS } \\
\text { status }\end{array}$ \\
\hline \multirow{7}{*}{$\begin{array}{l}\text { Yverdon- les- } \\
\text { Bains }\end{array}$} & Bains & 114 & 1 & 115 & 0 & None \\
\hline & Général Guisan & 67 & 4 & 71 & 0 & None \\
\hline & $\begin{array}{l}\text { Quatre- } \\
\text { Marronniers }\end{array}$ & 83 & 1 & 84 & 0 & None \\
\hline & Moulins (NS) & 74 & 14 & 88 & 2 & On-going \\
\hline & Villette (NS) & 92 & 6 & 98 & 7 & Complete \\
\hline & $\begin{array}{l}\text { Pierre-de-Savoie } \\
\text { (NS) }\end{array}$ & 72 & 5 & 77 & 9 & Complete \\
\hline & Total & 502 & 31 & 533 & & \\
\hline \multirow[t]{3}{*}{ Gland } & Gland Nord (NS) & 82 & 20 & 102 & 7 & Complete \\
\hline & Gland Sud (NS) & 83 & 20 & 103 & 7 & Complete \\
\hline & Total & 165 & 40 & 205 & & \\
\hline \multirow[t]{3}{*}{ Morges } & Morges Nord & 94 & 0 & 94 & 0 & None \\
\hline & Morges Sud & 115 & 0 & 115 & 0 & None \\
\hline & Total & 209 & 0 & 209 & & \\
\hline Total & & 876 & 71 & 947 & & \\
\hline
\end{tabular}

$0=$ not at all to $4=$ definitely yes, $M=1.87, S D=0.82, \alpha=.90$ ). This scale was chosen because of the relevance of the questions to collectively taking initiative in the community, and is detailed in Appendix B in Data S1.

\subsection{4 | Cognitive SC}

Cognitive SC was assessed using Sampson, Raudenbush, and Earls' (1997) five-item social cohesion scale (e.g., "people in this neighborhood can be trusted," $0=$ do not agree at all to $5=$ definitely agree, $M=2.13$, $S D=.72, \alpha=.81)$.

\subsection{5 $\quad$ Structural SC}

Structural SC was assessed by asking participants to indicate the number of different community associations they were members of outside of the NS intervention, out of a choice of 14 (e.g., "sports," "games," "leisure," "religion," "solidarity," "environmental initiatives," "other"). We took the sum of these memberships, $M=1.05, S D=1.32$.

\subsection{6 | Symptoms of depression}

Symptoms of depression were measured using the 10-item Revised Centre for Epidemiological Studies Depression Scale (CES-D-R-10) (Radloff, 1977) (e.g., "I was bothered by things that don't usually bother me"). The responses of each question ranged from $0=$ rarely or none of the time (less than 1 day) to $3=$ all of the time (5-7 days). We used 
the mean score of each individuals responses, $M=0.67, S D=0.46, \alpha=.75$. Following the recommendations on the CES-D-10 score calculations (Andresen, Malmgren, Carter, \& Patrick, 1994), we did not compute the mean score if there were more than two items missing. We decided to use symptoms of depression for the purposes of this analysis, as we were not working with a clinical population. However, we conducted supplementary analyses using the CES-D-R-10 recommended cut off scores of 10 or higher as screening positive for depression (Appendix C in Data S1).

\section{6 | RESULTS}

\section{1 | Overview of the analytical strategy}

We tested our two models using structural equation modelling (SEM) with Maximum Likelihood estimation using Stata14 software (StataCorp, 2015). We chose to deal with missing data using list-wise deletion. We did not use multilevel models, as our sample size at the higher level was not large enough (10 neighbourhoods). In our case, the main advantage of SEM was the flexibility to model complex relationships between exogenous focal predictors (individual participation in the NS, living in an area with the NS) and endogenous outcome variables (collaborative competence, structural SC, cognitive SC, symptoms of depression) simultaneously.

We built two SEMs testing the total, direct, and indirect effects of either participating in the NS (focal predictor variables of Model 1) or living in an area with the NS (focal predictor variables of Model 2) via collaborative competence (intermediate variable A), cognitive and structural SC (intermediate variables B1 and B2), and on symptoms of depression (outcome variable). Our models used parcels for parsimony reasons: Compared with latent factor analyses, SEMs based on parcelled data have fewer estimated parameters, fewer chances for residuals to be correlated, and reduced sampling error (see Little, Cunningham, Shahar, \& Widaman, 2002, p. 155). In addition to the Chi-squared of the model, we gathered the following fit indices to evaluate our SEMs: The comparative fit index (CFI), the root mean square error of approximation (RMSEA), and the standardized root mean square residual (SRMR). By convention, $\mathrm{CFI} \geq .95$ indicates that the model fit is better than the model fit of a null model, whereas RMSEA $\leq .06$ and SRMR $\leq .08$ indicate that the discrepancy between the predicted values and the observed values in the model is low (Hooper, Coughlan, \& Mullen, 2008; Kline, 2015). Figures 1 and 2 present the two models of interest.

Our two models did not include control variables, so we conducted multiple regressions that controlled for socio-demographic variables related to (a) participating in the NS and (b) living in a neighbourhood with an NS for each outcome variable (collaborative competence, structural and cognitive SC, and depressive symptoms). The sociodemographic control variables included age, gender, marital status, education, employment, financial satisfaction, and nationality. Key socio-demographic variables, such as age and gender, were not associated with our variables of interest (see Appendix D in Data S1 for more information). Finally, while we did not hypothesize that the effects of the NS interventions would spillover into the municipality, we conducted a third SEM model to check for spillover (Appendix E in Data S1).

\subsection{Individual participation in the NS and symptoms of depression (model 1)}

\subsection{1 | Total effects of NS and depression}

In line with our prediction, individual participation in the NS had a negative total effect on symptoms of depression, $B=-0.12,95 \% \mathrm{Cl}(-0.23,-0.01), p=.040$. 
$\chi^{2}(10, n=947)=340.84, p<.001 ; \mathrm{CFI}=1.00 ; \mathrm{RMSEA}<0.001 ; \mathrm{SRMR}=0.007$

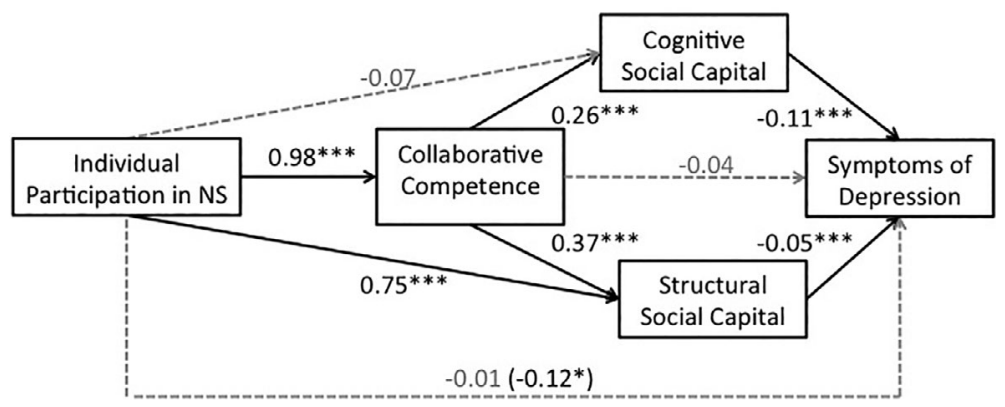

$\chi^{2}(10, n=947)=229.07, p<.001 ; \mathrm{CFI}=1.00 ;$ RMSEA $=0.003 ;$ SRMR $=0.008$

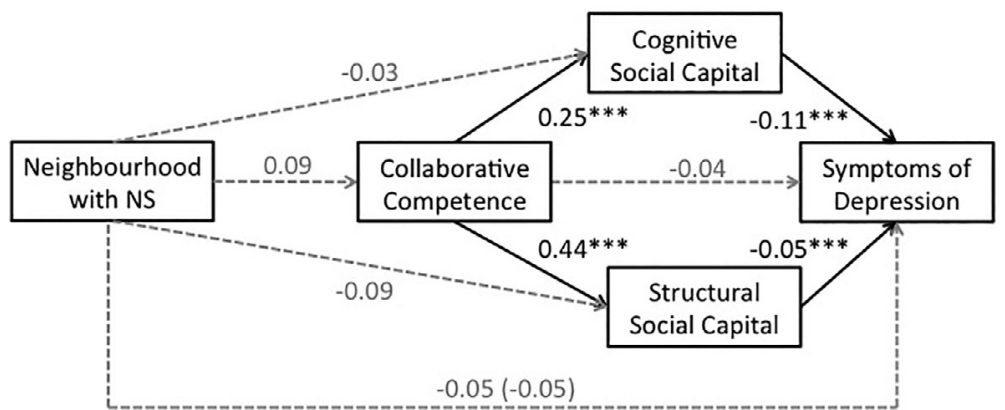

FIGURE 1 Model 1: Individual participation. Coefficients are nonstandardized; total effects are in parentheses; solid lines indicate significant path, whereas dashed lines indicate non-significant paths; ${ }^{* * *} p<.001,{ }^{*} p<.05$
FIGURE 2 Model 2: Living in a neighbourhood with an NS. Coefficients are non-standardized; total effects are in parentheses; solid lines indicate significant path, whereas dashed lines indicate non-significant paths; ${ }^{* * *} p<.001$

\subsubsection{NS, collaborative competence, SC, and depression}

We observed that individual participation in the NS was positively associated with collaborative competence, $B=0.98,95 \% \mathrm{Cl}(0.79,1.16), p<.001$, and structural SC, $B=0.75,95 \% \mathrm{Cl}(0.43,1.07), p<.001$, but was not significantly associated with cognitive SC, $B=-0.07,95 \% \mathrm{Cl}(-0.24,0.11), p=.461$.

Collaborative competence was positively associated with both cognitive SC, B $=0.26,95 \% \mathrm{Cl}(0.20,0.31)$, $p<.001$, and structural SC, $B=0.37,95 \% \mathrm{Cl}(0.26,0.47), p<.001$. It had a marginal effect on symptoms of depression, $B=-0.04,95 \% \mathrm{Cl}(-0.08-0.00), p=.051$.

Both cognitive and structural SC were negatively associated with symptoms of depression, $\mathrm{B}=-0.11,95 \% \mathrm{Cl}$ $(-0.15,-0.07), p<.001$, and $B=-0.05,95 \% \mathrm{Cl}(-0.07,-0.03), p<.001$, respectively.

\subsection{3 | Indirect effects of participating in the NS on depression}

The indirect effects were calculated by testing the product of the relevant paths (calculations were based on the so-called "delta method"). In the mediation framework, a significant indirect effect is indicative of a mediational process (Yzerbyt, Muller, Batailler, \& Judd, 2018). Consistent with our hypothesized model, we found that, for individuals, participating in the NS was negatively associated with symptoms of depression. Individual participation in the NS had a negative first-order indirect effect on symptoms of depression through structural SC, $B=-0.04,95 \% \mathrm{Cl}(-0.06,-0.01), p=.002$, a second-order indirect effect through collaborative competence and structural SC, $B=-0.02,95 \% \mathrm{Cl}(-0.03,-0.01), p=.001$, and second-order indirect effect through collaborative competence, cognitive SC, and symptoms of depression, $B=-0.03,95 \% \mathrm{Cl}(-0.04$, $-0.01), p<.001$. 
Fit indices for this first general model were all above the threshold, showing that the fit between the hypothesized model and the data was acceptable.

\subsection{Living in a neighbourhoods with the NS and symptoms of depression (model 2)}

\subsection{1 | Total effects of NS and depression}

Living in a neighbourhood with an NS was not significantly associated with symptoms of depression, $B=-0.05,95 \%$ $\mathrm{Cl}(-0.11,0.01), p=.076$.

\subsection{2 | NS, collaborative competence, SC, and depression}

We observed that living in a neighbourhood with an NS was not significantly associated with collaborative competence, $B=0.09,95 \% \mathrm{Cl}(-0.14,0.19), p=.089$, structural SC, $B=-0.09,95 \% \mathrm{Cl}(-0.25,0.07), p=.287$, cognitive SC, $B=-0.03,95 \% \mathrm{Cl}(-0.12,0.06), p=.488$, or depression, $B=-0.05,95 \% \mathrm{Cl}(-0.11,0.04), p=.067$.

Fit indices for this second general model were all above the threshold as well.

\section{7 | DISCUSSION}

This study found that individual participation in the NS is indirectly associated with better mental health, but found no association between living in a neighbourhood with an NS and mental health. Our results showed that individual participation in the NS was positively associated with collaborative competence and structural SC. By extension, individual participation in the NS indirectly predicted symptoms of depression via collaborative competence and both cognitive and structural SC.

As expected, participating in the NS predicted collaborative competence and structural SC. Surprisingly, participating in the NS only indirectly predicted cognitive SC via collaborative competence. This may be because cognitive SC focuses on perceptions, which may be more difficult to change than structural SC, which focuses on participation and membership. This finding is in line with anotherstudy that showed that NS participants experienced an increase in structural, but not cognitive SC after one year of participating in the NS (Ehsan \& Spini, 2020). However, the finding that participation in the NS directly predicted structural SC may have also been due to response errors in the questionnaires: While the questionnaires explicitly asked for membership in activities outside the NS, it is possible that individuals included NS activities in their responses. Our additional analyses (Appendix D in Data S1) also showed that more frequent individual participation in the NS was associated with more collaborative competence, showing that more regular participation in CBPI may be linked to more benefits.

\section{1 | Limitations}

A key limitation is that this study uses cross-sectional data and cannot comment on the direction of causality. While the objective of the NS is to empower individuals to participate, we cannot infer the direction of this relationship with our data: It is possible that individuals with high levels of both collaborative competence and SC participate more in the NS. Furthermore, our data cannot be used to infer whether developing collaborative competence is a mechanism that leads to SC, or whether SC is needed to develop collaborative competence. Despite this, our theoretical framework stemmed from Christens' (2012) understanding of collaborative competence (the ability to build social relationships) as a predictor of SC, and not vice versa. Even though the natural experiment comparing existing 
communities with and without the intervention provides high ecological value, it would have been ideal to compare the same communities before and after they received the NS intervention, in order to further understand these mechanisms.

Another limitation is that we had a small sample of respondents who participated in the NS. Our findings may not be applicable to all NS participants, and individuals who chose to respond to our survey may have been different than those who did not (selection bias). NS activities are also open to all community members, meaning that individuals from control neighbourhoods in one municipality could participate in NS activities in other neighbourhoods. This limits the generalizations we can draw from our second model, which focused on whether individuals lived in a neighbourhood with or without an NS. We tried to account for this by controlling for the municipality in our additional analyses.

Our research focused on an already existing intervention. This approach led to a discrepancy between the aims of the intervention and our research, as the interventions were not explicitly designed to promote mental health in older adults. We applied a research-lens to an existing intervention, which is not ideal for regular monitoring and evaluation practice. Theoretical decisions we took may have influenced the findings. For example, we chose to look at cognitive and structural SC because they are the most widely utilized in health research. We may have had different results if we had measured network SC (bonding and bridging dimensions). Furthermore, the only sub-measure of collaborative competence that we are aware of is for relational empowerment as a whole (Cheryomukhin \& Peterson, 2014). We instead chose to focus on collaborative competence, and measured it with an adapted measure of self-efficacy, which, in our opinion, reflects Christens' (2012) definition of collaborative competence.

\section{2 | Contributions}

Current research concerning SC interventions on mental health in older adults has been limited by short-term and top-down approaches to building SC, as well as the lack of explanatory psychological resources in whether and how SC is promoted. This study shows how existing community interventions can be associated with psychological mechanisms that are, in turn, related to SC and mental health in communities of older adults. To our knowledge, this is the first empirical study looking at the relationship between collaborative competence and cognitive and structural SC. This study shows that collaborative competence could have an important role to play in understanding how CBPI are related to SC and subsequently mental health. To date, few empirical studies have investigated the mechanisms linking collaborative competence and SC. Although more longitudinal is needed to draw causal inferences, this research begins to address this gap. Furthermore, researchers have recommended accounting for different contexts when studying SC interventions for health (Carpiano \& Moore, 2020), and this study is one of the first to provide information on SC interventions and mental health in the Swiss context.

The natural setting of this experiment helped provide insight on the importance of studying existing interventions to see how they may indirectly promote mental health, and we took both neighbourhood and individual participation into consideration. The interdisciplinary approach used in this research allowed us to better understand the complexity of a CBPI for older adults, and highlights the need for more collaborative efforts in promoting mental health for the ageing population. In line with Burgess et al.'s (2020) recommendations, this research contributes to knowledge on how social interventions that are not intended for mental health can have consequences for mental health promotion. Lastly, the Swiss government has identified promoting healthy ageing as a public health priority for the decade to come, and has developed a recent interest in social initiatives (OFSP, 2019). Understanding how existing initiatives in Switzerland are already influencing mental health for older adults can help inform these policies.

\section{3 | Recommendations and future directions}

Existing community-based interventions may indirectly predict structural, but not cognitive SC. SC interventions are complex, and can be a double-edged sword depending on who is able to access them: They can provide benefits for 
some while simultaneously reproducing inequalities for others (Glaeser, 2016). The NS are only available in neighbourhoods of municipalities who choose to to fund the NS. Individual participation in the NS is also voluntary and attracts people who are both willing and able to participate. This is is not always inclusive, and the NS can sometimes exclude actors, such as minority groups, who could gain the most from these types of interventions (Ehsan, Bolano, Guillaume-Boeckle, \& Spini, 2020). Future studies should consider which groups are able to access interventions and why.

Researchers interested in promoting collaborative competence, SC, and mental health should collaborate with existing community groups in order to help create evidence-based monitoring and evaluation frameworks that are longitudinal and context-specific. These frameworks should be created before the beginning of the intervention when possible, and approached from interdisciplinary perspectives. We encourage more dialogue between community, social, and public health policy and practice, and recommend more collaboration between these actors to develop interventions that are contextually appropriate.

\section{8 | CONCLUSION}

This study is an example of how researchers can use evidence from existing initiatives and natural experiments to add to the body of evidence concerning SC interventions and mental health in different contexts. Psychological constructs, such as collaborative competence, can play an important role in fostering SC, and should be taken into consideration when designing future interventions for SC and mental health. Participating in community interventions can have a positive indirect effect on the mental health of older adults.

\section{ACKNOWLEDGEMENTS}

This publication benefited from the support of the Swiss National Centre of Competence in Research LIVESOvercoming vulnerability: Life course perspectives, financed by the Swiss National Science Foundation. We warmly thank Pro Senectute Vaud and the Neighbourhoods in Solidarity team for their on-going partnership and collaboration. Finally, we would also like to thank Hannah Klaas for her feedback.

\section{CONFLICT OF INTEREST}

The authors declare that they have no conflict of interest.

\section{COMPLIANCE WITH ETHICAL STANDARDS}

The authors of this manuscript have complied with APA ethical principles in their treatment of individuals participating in the research, program, or policy described in the manuscript. The research has been approved by the Swiss Ethical Committee in the Canton of Vaud.

\section{ORCID}

Annahita Ehsan (D) https://orcid.org/0000-0002-5281-6891

Nicolas Sommet (1) https://orcid.org/0000-0001-8585-1274

Davide Morselli (iD) https://orcid.org/0000-0002-1490-9691

\section{REFERENCES}

Andresen, E. M., Malmgren, J. A., Carter, W. B., \& Patrick, D. L. (1994). Screening for depression in well older adults: Evaluation of a short form of the CES-D. American Journal of Preventive Medicine, 10, 77-84.

Bojorquez-Chapela, I., Manrique-Espinoza, B. S., Mejía-Arango, S., Solís, M. M. T. R., \& Salinas-Rodríguez, A. (2012). Effect of social capital and personal autonomy on the incidence of depressive symptoms in the elderly: Evidence from a longitudinal study in Mexico. Aging \& Mental Health, 16, 462-471. 
Botes, L., \& Van Rensburg, D. (2000). Community participation in development: Nine plagues and twelve commandments. Community Development Journal, 35(1), 41-58.

Büla, C., Beetschen, P., David, S., Gay, C., Goy, R., Giger, T., ... Viens Python, N. (2012). Politique cantonale vieillissement et santé: Rapport du comité d'experts transmis à Monsieur le Conseiller d'Etat Pierre-Yves Maillard le 8 décembre 2011. Lausanne: Canton de Vaud.

Burgess, R. A., Jain, S., Petersen, I., \& Lund, C. (2020). Social interventions: A new era for global mental health? The Lancet. Psychiatry, 7(2), 118-119.

Carpiano, R. M., \& Moore, S. (2020). So What's next? Closing thoughts for this special issue and future steps for social capital and public health. Social Science \& Medicine, 257, 113013.

Cheryomukhin, A., \& Peterson, N. A. (2014). Measuring relational and intrapersonal empowerment: Testing instrument validity in a former soviet country with a secular Muslim culture. American Journal of Community Psychology, 53, 382-393.

Christens, B. D. (2012). Toward relational empowerment. American Journal of Community Psychology, 50, 114-128.

Christens, B. D., Winn, L. T., \& Duke, A. M. (2016). Empowerment and critical consciousness: A conceptual cross-fertilization. Adolescent Research Review, 1(1), 15-27.

Coll-Planas, L., Nyqvist, F., Puig, T., Urrútia, G., Solà, I., \& Monteserín, R. (2017). Social capital interventions targeting older people and their impact on health: A systematic review. Journal of Epidemiology and Community Health, 71, 663-672.

Canton de Vaud. (2018). Rapport sur la politique de santé du canton de Vaud 2018-2022. Lausanne: Canton de Vaud.

Duraiappah, A. K., Roddy, P., \& Parry, J. E. (2005). Have participatory approaches increased capabilities? Winnipeg, Canada: International institute for sustainable development.

Ehsan, A., Bolano D., Guillaume-Boeckle S., \& Spini D. (2020). Reducing loneliness in older adults: looking at locals and migrants in a Swiss case study. European Journal of Ageing, http://dx.doi.org/10.1007/s10433-020-00577-4.

Ehsan, A., Klaas H. S., Bastianen A., \& Spini D. (2019). Social capital and health: A systematic review of systematic reviews. SSM - Population Health, 8, 100425.

Ehsan, A., \& Spini D. (2020). Place, social capital, and mental health: A mixed-methods case study of a community-based intervention. Health \& Place, 64, 102386.

Ehsan, A. M., \& De Silva, M. J. (2015). Social capital and common mental disorder: A systematic review. Journal of Epidemiology and Community Health, 69, 1021-1028.

Ellison, E. R. (2017). Collaborative competence as relational praxis among community organizers: The reproduction of, and resistance to, Systems of Oppression. (Doctoral dissertation). UC Santa Cruz.

Faul, F., Erdfelder, E., Buchner, A., \& Lang, A. G. (2009). Statistical power analyses using G* power 3.1: Tests for correlation and regression analyses. Behavior Research Methods, 41, 1149-1160.

Flores, E. C., Fuhr, D. C., Bayer, A. M., Lescano, A. G., Thorogood, N., \& Simms, V. (2018). Mental health impact of social capital interventions: A systematic review. Social Psychiatry and Psychiatric Epidemiology, 53, 107-119.

Forsman, A. K., Nordmyr, J., \& Wahlbeck, K. (2011). Psychosocial interventions for the promotion of mental health and the prevention of depression among older adults. Health Promotion International, 26(suppl_1), i85-i107.

Gallagher, H. C., Block, K., Gibbs, L., Forbes, D., Lusher, D., Molyneaux, R., ... Bryant, R. A. (2019). The effect of group involvement on post-disaster mental health: A longitudinal multilevel analysis. Social Science \& Medicine, 220, $167-175$.

Glaeser, S. (2016). The irony of social trust: Individual-level and contextual-level links with protest intention and radical right support in Switzerland. Journal of Community \& Applied Social Psychology, 26, 110-124.

Hall, B. J., Bolton, P. A., Annan, J., Kaysen, D., Robinette, K., Cetinoglu, T., ... Bass, J. K. (2014). The effect of cognitive therapy on structural social capital: Results from a randomized controlled trial among sexual violence survivors in The Democratic Republic of the Congo. American Journal of Public Health, 104, 1680-1686.

Haslam, C., Cruwys, T., Haslam, S. A., Dingle, G., \& Chang, M. X. L. (2016). Groups 4 health: Evidence that a social-identity intervention that builds and strengthens social group membership improves mental health. Journal of Affective Disorders, 194, 188-195.

Hooper, D., Coughlan, J., \& Mullen, M. (2008). Structural equation modelling: Guidelines for determining model fit. Electronic Journal of Business Research Methods, 6, 53-60.

Jeanrie, C. (1997). La mesure du Sentiment d'Efficacité Personnelle: Outils et principes d'élaboration. Mesure et Evaluation en Education, 19, 41-68.

Kawachi, I., \& Berkman, L. (2000). Social cohesion, social capital, and health. Social Epidemiology, 174, 190.

Kline, R. B. (2015). Principles and practice of structural equation modeling. New York, NY: Guilford publications.

Langhout, R. D., Collins, C., \& Ellison, E. R. (2014). Examining relational empowerment for elementary school students in a yPAR program. American Journal of Community Psychology, 53(3-4), 369-381.

Little, T. D., Cunningham, W. A., Shahar, G., \& Widaman, K. F. (2002). To parcel or not to parcel: Exploring the question, weighing the merits. Structural Equation Modeling, 9, 151-173.

McKenzie, K., \& Harpham, T. (2006). Social capital and mental health. London, UK: Jessica Kingsley Publishers. 
Murayama, H., Nishi, M., Matsuo, E., Nofuji, Y., Shimizu, Y., Taniguchi, Y., ... Shinkai, S. (2013). Do bonding and bridging social capital affect self-rated health, depressive mood and cognitive decline in older Japanese? A prospective cohort study. Social Science \& Medicine, 98, 247-252.

Office fédéral de la santé publique (OFSP). (2019). Stratégie nationale Prévention des maladies non transmissibles. Berne: Confédération Suisse.

Perkins, D. D., Hughey, J., \& Speer, P. W. (2002). Community psychology perspectives on social capital theory and community development practice. Community Development, 33, 33-52.

Phillips, G., Bottomley, C., Schmidt, E., Tobi, P., Lais, S., Yu, G., ... Clow, A. (2014). Well London Phase-1: Results among adults of a cluster-randomised trial of a community engagement approach to improving health behaviours and mental well-being in deprived inner-city neighborhoods. Journal of Epidemiology and Community Health, 68, 606-614.

Radloff, L. S. (1977). The CES-D scale: A self-report depression scale for research in the general population. Applied Psychological Measurement, 1, 385-401.

Saito, T., Kai, I., \& Takizawa, A. (2012). Effects of a program to prevent social isolation on loneliness, depression, and subjective well-being of older adults: A randomized trial among older migrants in Japan. Archives of Gerontology and Geriatrics, 55, 539-547.

Sampson, R. J., Raudenbush, S. W., \& Earls, F. (1997). Neighborhoods and violent crime: A multilevel study of collective efficacy. Science, 277, 918-924.

Shiell, A., Hawe P., \& Kavanagh S. (2020). Evidence suggests a need to rethink social capital and social capital interventions. Social Science \& Medicine, 257, 111930.

StataCorp, L. P. (2015). Stata statistical software: Release 14.[computer program]. College Station, TX: StataCorp LP.

Steptoe, A., Shankar, A., Demakakos, P., \& Wardle, J. (2013). Social isolation, loneliness, and all-cause mortality in older men and women. Proceedings of the National Academy of Sciences, 110, 5797-5801.

Statistique Vaud. (2017). Bilan démographique, grands groupes d'âges et population étrangère, par commune, Vaud, 2010-2015. Lausanne. Canton de Vaud.

Wallerstein, N. B., \& Duran, B. (2006). Using community-based participatory research to address health disparities. Health Promotion Practice, 7(3), 312-323.

Yzerbyt, V., Muller, D., Batailler, C., \& Judd, C. M. (2018). New recommendations for testing indirect effects in mediational models: The need to report and test component paths. Journal of Personality and Social Psychology, 115, 929-947.

Zimmerman, M. A. (2000). Empowerment theory. In Handbook of community psychology (pp. 43-63). Boston, MA: Springer.

Zwygart, M., Plattet, A., \& Spini, D. (2018). "Neighborhood in solidarity": A community development methodology that emerged throughout an action research experience. Action Research, 16, 65-81.

\section{SUPPORTING INFORMATION}

Additional supporting information may be found online in the Supporting Information section at the end of this article.

How to cite this article: Ehsan A, Sommet N, Morselli D, Spini D. Collaborative competence, social capital, and mental health: A cross-sectional analysis of a community-based intervention for older adults.

J Community Appl Soc Psychol. 2020;1-15. https://doi.org/10.1002/casp.2481 